\title{
The Strategies of Fostering Students' Cross-Cultural Awareness in Secondary School English Teaching
}

\author{
Keqiang $\mathrm{Xu}^{1,2}$ \\ ${ }^{1}$ Research Centre for Basic Education, Southwest University, Chongqing, China \\ ${ }^{2}$ Faculty of Education, Southwest University, Chongqing, China \\ Email:kqxu@swu.edu.cn
}

Received 5 June 2016; accepted 20 June 2016; published 23 June 2016

Copyright (C) 2016 by author and Scientific Research Publishing Inc. This work is licensed under the Creative Commons Attribution International License (CC BY). http://creativecommons.org/licenses/by/4.0/ c) (i) Open Access

\begin{abstract}
Based on the previous study on the framework of cultivating cross-cultural awareness, this study focuses on strategies in practice for Secondary School English teaching. It aims at explaining how to effectively promote the target culture teaching and learning and develop key competencies of cross-cultural awareness in the context of Chinese learners of English. The author proposes different methods and strategies for cultivating Secondary English students' cross-cultural awareness in accordance with features of two aspects of teaching and learning, namely at curricular and extracurricular time.
\end{abstract}

\section{Keywords}

\section{Strategies, Cross-Cultural Awareness, Secondary School English}

\section{Introduction}

With the globalization of the world economy and the popularization of international exchange, the world is becoming a "global village", where people with different colors of skin, using different languages and from different countries as well as different cultural backgrounds are living together just like the "global villagers". China is in desperate need of people who are familiar with foreign cultures and capable of communicating accurately and appropriately in cross-cultural situations. This is a new challenge for all the levels of English teaching and learning. Especially, secondary school education as most important stage of basic education. It needs to help students build solid foundation for language proficiencies and cross-cultural communicative competency. Crosscultural communication requires two types of competence, namely, linguistic competence and socio-cultural competence, which lead to changes in the goals, objectives, methods, strategies of foreign language teaching 
accordingly. However, in practice we realize, with years of English study, that students often have lots of disagreements, misunderstanding, and even culture shocks when they communicate with the native speakers of English. Those breakdowns and misunderstandings are due to the lack of cultural knowledge of the country whose language is being learned. Students need to enhance their cross-cultural communicative competence. In the previous study, the author thinks that integrating culture teaching into English teaching, cultivating students' cross-cultural awareness, and developing their cross-cultural communicative competence, are the key factors leading to successful cross-cultural communication in the future. It is regulated in the English Curriculum Standards for Compulsory Education $(2001,2011)$ that one of the goals of English teaching is to cultivate students' cross-cultural communicative competence [1] [2]. To achieve this goal, students are required to increase their cultural knowledge and improve their cross-cultural awareness. However students' knowledge of English culture is far from satisfactory with many years of English studies. It is the author's belief that cultivating students' cross-cultural awareness through establishing a model of culture teaching and learning is more effective and practical than through isolated classroom instruction. Thus, the conceptual framework of cultivating Secondary English students' cross-cultural awareness is raised and illustrated in detail with respect to the goal, principle, content of culture teaching. The author proposes different methods for cultivating Secondary English students' cross-cultural awareness in accordance with features of two aspects of teaching and learning, namely at curricular and extracurricular time.

Besides, under the pressure to pass Zhongkao and Gaokao, students spend much time memorizing the vocabulary and grammar mechanically, not considering about the cultural meaning of some words or foreign cultures. So they couldn't learn how to use English words authentically. Meanwhile, the English teachers fail to foster the students' cross-cultural awareness by successfully putting culture teaching into teaching activities. On the contrary, they teach the English language nearly without culture instructions. Thus, in the practical use of English language, it is found that students cannot communicate with people from other cultures at ease. To sum up, the current situation of English teaching is rather disappointing not only from the system itself but also from the school-based initiative of English curriculum reform. Considering the problems existing in the current English teaching and the objective and requirements of the English Curriculum Standards, it is very obvious that the cultivation of cross-cultural awareness needs to become an essential part in foreign language education. Furthermore, lots of efforts should be made to integrate cultural elements into language teaching and learning for the cultivation of cross-cultural awareness. Apart from the theoretical understanding of the frameworks for fostering cross-cultural awareness, it is very imperative to develop strategies in practice.

\section{Strategies to Cultivate Students' Cross-Cultural Awareness}

During the process of Secondary School English teaching (SSET), teachers will try to lay a sound foundation for cultural understanding and cross-cultural awareness. The acquisition of cultural knowledge leads to two results: one is to accumulate the related knowledge about the target culture, the other is to help cultivate students' crosscultural awareness. Cross-cultural awareness refers to the sensibility and insight to the differences and similarities between target culture and native culture, and the self-consciousness of rearranging one's language understanding input (listening, reading) and language output (reading, writing, speaking) according to the target culture when using the language, therefore, in the process of teaching cultural knowledge, teachers should also cultivate students' cross-cultural awareness initiatively. Otherwise, the teaching of cultural knowledge may be only regarded as a process of knowledge accumulation, which is opposite to the ultimate goals of English teaching.

It is now widely accepted among foreign language educators that to establish a system of cultivating EFL learners' cross-cultural awareness is more effective than to simply instill cultural ideas into learners' minds. Culture is always in a dynamic state, and we can never teach it as static and isolated. SSET teachers' task is to develop students' capability of how to learn rather than solve the problem of what to learn. Therefore, SSET teachers are demanded to make much more efforts to enlarge the learners' scope of cultural knowledge and improve their cultural abilities. The process of cultivating SSET students' cross-cultural awareness may be divided into two aspects, namely to cultivate students' cross-cultural awareness at curricular time and that at extracurricular time. Thus, the strategies to cultivate SSET students' cross-cultural awareness will be discussed accordingly.

\subsection{Cultivation of Cross-Cultural Awareness at Curricular Time}

Secondary School English teaching at curricular time is the main field for cultivating students' cross-cultural 
awareness by the means of the methodology and teaching of cultural knowledge. And textbook plays a very important role in the context of Secondary School English teaching and learning. Junior English (go for it, JE for short) and New Senior English (NSE for short) published by People's Education Press are mainstream English textbooks that are widely used in secondary school throughout China at present. JE and NSE was based on some principles of the Learner-Centered and Topic-Based Modes, a brand-new classroom teaching model. It is in an attempt to apply communicative approach in EFL in Chinese context and it aims to help students acquire not only knowledge of the language forms but good communicative competence in foreign language teaching. It meets learners' communicative needs in life and future work. Its novel, authentic, lively and diversified material has benefited the secondary students greatly, especially in the aspect of listening and speaking. The following parts attempt to propose some strategies to cultivate secondary students' cross-cultural awareness through the development of communicative competence at curricular time when teachers are using JE and NSE as textbooks.

\subsubsection{Applying Interactive Teaching Approach}

Interactive teaching approach is an effective way to foster students' cross-cultural awareness. Interaction is the collaborative exchange of thoughts, feelings, or ideas between two or more people resulting in a reciprocal effect on each other. Interaction is the heart of communication; it is what communication is all about. We send messages; we receive them; we interpret them in a context; we negotiate meanings; and we collaborate to accomplish certain purposes. Theories of communicative language teaching emphasize the importance of interaction as human beings use language in various contexts to "negotiate" meaning (Brown, 2001), or simply stated, to get one idea out of one's head and into the head of another person and vice versa [3]. In a word, it is the interaction between the teacher and students, students and the teacher, students and students, students and authors of the text, students and the community that speaks the language (Rivers, 1997: 6) [4]. Communicative competence implies that language learning takes contextual difference, and learner variability as its core and the major goal of current language learning is cross-cultural communication. Therefore, the cultivating of cross-cultural awareness means helping learners' obtain the sense that they are equal but different in cross-cultural communication, to know how and where they are different, and to search for a third perspective of viewing cross-cultural events. Thus, through interaction, interactive English teaching approach provides us with a feasible teaching method of cultivating cross-cultural communicative competence and cross-cultural awareness.

The current discussion adopt two aspects to explain: one is the interactive teaching approach in listening and speaking course, and the other is the interactive teaching approach in reading and writing course.

\section{1) Interactive Teaching Approach in Listening and Speaking Course}

In our traditional listening and speaking classes, teachers dominate the class. They lecture, explain grammar points, conduct drills, sometimes they let whole-class discussions in which each student might get a few seconds of a class period to talk and the class no interactive activities. In integrated course of Junior English (JE) and New Senior English (NSE), teaching listening and speaking by interactive approach become more flexible and practicable, for the organization of the contents and topic-based modes for each unit are explicit and beneficial. As shown in the description of the course aim, "four languages skills" in each unit are consolidated systematically. It suggests that a teacher can give up some control of the classroom, but not lose control it and try to create a learner-centered environment. In interactive listening and speaking course, methods as group work helps to solve the problem of classes that too large to offer many opportunities to speak, and it can generate interactive language in speaking and listening. Group work is the most suitable interactive teaching approach in JE and NSE classroom especially for large-scale class. Group work includes game, role-play and simulations, projects, brainstorming, information gap, jigsaw principle, opinion exchange. When teaching this course, we mainly concentrate on the integrated course of "Listening-Centered Activities" in each unit to carry out listening and speaking practice with the above-listed items of group work at due course. And teachers' task is not just on how to teach listening and speaking skills, but on what students are "doing" when their listen and speak. According to Brown (1997: 243), the suggestion for the performance in interactive listening and speaking classroom include three aspects: intensive, responsive and interactive performance, which definitely gives us some illuminations and orients our teaching listening and speaking in Junior English (JE) and New Senior English (NSE) [3].

Intensive speaking goes one step beyond imitative to include any speaking performance that is designed to practice some phonological or grammatical aspect of language. A significant proportion of classroom listening 
and speaking activity consists of short stretches of teacher language designed to elicit immediate responses. The students' task in such listening is to process the teacher talk immediately and to fashion an appropriate reply.

Responsive performance includes: asking questions, giving commands, seeking clarification, and checking comprehension.

Interactive language teaching stresses the importance of providing learners with more activities to interact directly with the target language - to require it by using it rather than to learn it by studying it. Students actively participate in discussions, debates, conversations, role-play, and other pair and group work.

\section{2) Interactive Teaching Approach in Reading and Writing Course}

In reading and writing interactive classroom, teacher should use text and task to facilitate interaction between students and teacher, students and materials, students and their fellow students. According to Carrell (1988: 98), in interactive classroom, the teacher can divide their reading techniques into pre-reading, during-reading, and after-reading [5]. For teaching JE and NEC, the task-based organization for the reading in each unit is called "Reading-Centered Activities", which is in accordance with Carrell's ideas. And "Reading-Centered Activities" are divided into "In-Class Reading” and "After-Class Reading” and altogether are consisted of three authentic texts. Before students read, teachers should spend some time introducing a topic, encouraging skimming, scanning, and activating schemata. Students can bring the best of knowledge and skills to a text. Pre-reading activities should be selected according to the experience and interest of students. Students should be introduced to the situations of a pictorial collage which generates expectations that will be useful in anticipating and predicting the content of the passage that will be read. Teacher may ask students questions associated with the title of the reading passage or the collage of pictures. Students will read the text with schemata in mind and the self-raised questions which they would like to find question. In while-reading phase, in order to further enhance interaction with the text and among students, teachers should stimulate work in pairs and offer them opportunity to work together and learn from each other. After finishing assigned reading, teacher may check students' comprehension for the text. The teacher can ask students to identify main and subordinate ideas, to summarize or retell parts of the text, to discuss viewpoints represented by persons and cultural significance in the text, to develop a different conclusion, and to conduct group discussion on the participates' awareness of the action and why the author chose to develop the content as he or she did (Rivers, 1997: 79) [4]. Teachers may select some of the activities to increase students' interaction with the text. For instance, students may look for specific information, such as selecting a meal from a menu or identifying times of arrival and departure in airline or railway schedules etc. Students read a story with the ending deleted, and then they try to make up an ending consistent with the story. Students read a specially constructed passage and correct sentences that contain wrong information. In a word, integrated-skills approaches to language teaching emphasize the interrelationship of skills. Reading ability will definitely best be developed in association with writing, listening, and speaking activity.

Writing can involve lively interaction with one another, with instructors, and with individuals outside of the daily classroom environment. Interactive writing is a tool for learning and not just a means to demonstrate learning of one of the major contributions of the research into the writing process (Gaudiani, 1981: 57) [6]. In interactive writing classroom, we may take Ur (1996)'s suggestion that designing interactive writing activities should be based on the principle of providing as much authentic writing as possible as our guidance [7]. Secondly, we may connect reading and writing techniques. Just as Raimes asserted in 1983, "writing is a way of reading better because it requires the learners to reconstruct the structure and meaning of ideas expressed by another writer" [8]. Students learn to write in part by observing or reading, the written words. And they can gain important insights both about how they should write and about what subject that may become the topic of their writing by reading and learning a variety of relevant types of text.

\subsubsection{Comparing Cultural Difference}

In secondary English teaching, some students are often found at a loss about what the author wants to get across even though there is no new word and the grammar is clear to them. The true reason is that they have little awareness of cultural difference. The awareness of cultural difference helps language learners towards an exact understanding and more appropriate use of the target language. The original text understanding is not only based on its language and grammar, but also based on how much culture one knows of the target country. It is generally accepted that culture factors play a crucial role in the teaching and learning of a foreign language, since language usage reflects the culture of a society.

The process of acquiring knowledge about foreign culture and using this knowledge in actual behavior is a 
process of cultural interaction in which both home and foreign cultures are brought together. By comparing systematically the contrastive qualities of the two culture systems, the teacher and learner can predict where the trouble spots will be and thus facilitate language teaching and learning as well as developing cultural awareness. Different categories in different languages can be used as a foundation for comparison through which we know the meaning and value of other cultures as well as our own. Through comparing native culture with target culture, students can easily make clear the differences and similarities between them. As Valdes points out:

Cross-cultural understanding is a recognition of the ways in which two cultures resemble one another as well as the ways in which they differ. Resemblances usually surface through an examination of the differences. General discussions and theories regarding cultural differences are necessary for consideration of specific cultures in their relationship to the target culture, and the one without the other is like a river without a current [9] (Valdes, 1986: 49).

In class, the teacher begins each discussion period with a presentation of one or more items in the target culture that are distinctly different from the students' culture. The discussion then centers on why these differences might cause problems. Chinese often say, “There can be no differentiation without contrast.” Through comparing native culture with target culture, the students can easily make clear differences and similarities between them and then rapidly develop cross-cultural awareness. We can compare the different custom and attitudes to the holidays or special days in Chinese culture and Western culture. Then the students will have a clear idea about the different custom, different cultural tradition, different value systems, different concepts of the Chinese and the Westerners. In short, only after coming to know, understand, and appreciate something of other cultures can one realize what values and behavior patterns of the new culture he has most needed to know. Such kind of comparison not only makes culture acquisition possible in language teaching but also helps students understand their home culture better and sometimes helps carry out patriotic education through JE and NEC.

\subsubsection{Teaching of Culture-Loaded Vocabulary}

Language can't exist separately from culture. Vocabulary or lexicon is the basic store or foundation to the language building. Naturally, it is influenced and conditioned by cultural factors, like the society, religion beliefs, customs, ways of life, value systems, conceptions of beauty, literary, etc., of a given people. Therefore, vocabulary or lexicon is the mirror or an index to a culture.

It is well-known that Nostrand (1974), Hammerly (1982) and Seelye (1984) and some other educators have pointed out that L2 learners, to reinforce the empathy for a second culture, should pay more attention to the cultural connotations of words and phrases [10]-[12]. Xu Guozhang (1980) proposes that L2 learners assess culturally-loaded words' relevance in English language learning. Sapir (1949) considers that vocabulary is a very sensitive index of the culture of people and Wierzbicka (1997) says, "Vocabulary is the best evidence of the reality of “culture”, in the sense of a historically transmitted system of “conceptions" and "attitudes” [13] [14]. The teaching of vocabulary involves the teaching of culture. Under the guideline of contrastive linguistics approach, according to the different functions in cross-cultural communication, those culture-loaded words and phrases can be regrouped into three types. They are: 1) words identical in designative meaning, but different in associations; 2) words identical or similar in associations, but different in designative meanings; 3) words with designative meanings and associative meanings available in only one of the two languages. In English, the culture-loaded words mainly include single words, phrases, proverbs, allusions and idioms. There are so many such words to be covered at one time. As to some allusions or idioms, unless one knows the stories related to them, he or she really cannot capture their real meaning, So it is necessary for the teachers to throw light on them about these "trap” words. As Will Carleton suggests “Careful with fire', is good advice, we know: 'Careful with words’, is ten times doubly so” (Deng \& Liu, 1989: 7).

When teaching vocabulary, it is very important for the teachers to explain cultural connotations of words and phrases. Through vocabulary teaching, teachers help students know about knowledge of history, literature and culture of both China and English-speaking countries. Comparing with the other textbooks at present use, new words and phrases of each unit in JE and NEC have their denotations and their connotations or associations which are closely related to their culture. Thus they may block students in learning English and trap the students in communication. For teaching of these new words in JE and NEC, here are some activities applicable in communicative classroom practice for teaching vocabulary. First, vocabulary instruction can be handled by using in-class or after-class authentic reading texts. In this type, learners are asked to focus on key words in a text, or 
to guess from the context, or to predict and activate vocabulary. Vocabulary-focused reading can serve as a springing board for storing and producing lexis. By reading, learners can make sense of the meanings of the text by way of their schematic knowledge and language knowledge. Second, speaking activities like role-play and story-telling can act as a medium for teaching vocabulary. For example, students may dramatize tourist guide and travelers with different roles assigned to them and focus on the words and phrases given to them in advance. Third, "gap" activities such as "information-gap activities" are beneficial in that participants are required to think over in order to convey their messages to others verbally. And in this way, lexical items can be drilled and internalized.

\subsubsection{Teaching Culture through Language Skills Training}

According to the law of language learning, the improvement of the ability of language use is based on a great deal of language input, especially on a great sum of reading and listening. JE and NEC design a variety of interesting activities including "Listening-Centered Activities" and "Reading-Centered Activities" for students to use the language, providing them with more opportunities to interact orally with their teachers and classmates to improve their communicative competence. In addition, these textbooks provide necessary cultural information for reading materials and some explanation of the difficult language points, saving a lot of time for teachers and students to perform more real-life communication activities by avoiding teachers' time wasting on explanations. Different from the traditional Secondary English textbooks, JE and NEC do not neglect the cultivation of students' language integrated-skills. One of the underlying principles for the JE and NEC series is that students are fully involved in class activities to develop their integrated skills of language. And just in accordance with the objective of secondary English teaching described in English Curriculum Standards (2011), JE and NEC attach much importance to cultivating students' ability, at the same time pays no less attention to their listening, speaking, and writing.

Secondary English education attaches great importance to the reading skill of students at the Basic English stage, as reflected in the course of "intensive reading". In Secondary English Teaching, reading has been considered to be the most important skill for students. Reading is the main channel for absorbing language knowledge and obtaining cultural information, and reading skill will be the main linguistic skill needed by most students in their work after graduation. In traditional reading class, English teachers present the main grammatical structures and language points of the texts through the process of paragraphing sentences one by one, which bears the result of students' understanding of only the superficial meaning of the reading material, but in many cases without a thorough comprehension of its deep implied meaning. We may integrate culture teaching in JE and NEC reading and listening class, which can provide useful background information about the texts. Culture teaching may give students access to the western customs and conventions, values and attitudes, collective imaginings and historical flames of reference. Through the process of comparisons, the thoughtful reader can perceive the qualities of the characters that make them worthy of loving and being loved. Thus, the cultural appreciation and understanding of the theme are sure to be greatly enhanced by the students.

To strengthen the teaching of writing, teachers should put more emphasis on the process of writing. The students need to be helped to develop and organize their thoughts and find the best way of expressing them. They will thus learn to handle written communication step by step. If they are helped along and feel they are learning at every step, they will be interested in writing and accomplish their work with ease.

In JE and NEC teaching, when integrating culture teaching with language skills training, a five-part cycle is proposed which involves: 1) Building the context for the text; 2) Modeling and deconstructing the text; 3) Joint construction of the text; 4) Independent construction of the text; 5) Linking the related texts.

Furthermore, we need to encourage interactive discourse and self-expression. Classroom activities that increase student-talk and promote interaction among students for communicative purposes will help us reach this goal.

\subsubsection{Supplying More Cultural Background}

Supplying cultural background is an essential way for teaching culture and then cultivating students' cultural awareness. Apart from those backgrounds supplied for each theme in the JE and NEC, teacher should try their best to dig up as much more cultural background as possible. As Coady (1979: 7) pointed out that "Background knowledge becomes an important variable when we notice as may have, that students with a western background of some kind learn English faster, on the average than those without such a background” [15]. And it is necessary for the teacher to introduce the background knowledge about the topic in the pre-reading stage. The 
awareness of pre-reading cultural background knowledge will enhance the understanding of the text better. We may teach culture by introducing and explaining cultural background knowledge in teaching materials. Supplying cultural background knowledge, a way to give students rich cultural information related to but beyond the passage being taught, will help students study the passage better and efficiently. Cultural background can be supplied to the text to be taught in order to stimulate students' interest in it and arouse the students' passion when studying.

In total, the supply of cultural background to passages could arouse students' interest and deepen their understanding to English culture, sometimes, it could make the texts easier to be learned, at other time, it could supply more cultural information to rich the text to get students to understand better. Chinese and English are totally two different languages belonging to two different cultures, which bear strong national culture and reflects different cultural information. In the process of learning, lacking of cultural background will result in too many difficulties and misunderstandings. As experts point out it's even difficult for teachers to understand the passages they know nothing or the passages that have nothing to do with their experiences. So in the SSET practice, teachers should supply appropriate cultural background to develop students' full understanding to the passages as well as cultivate students' cultural awareness.

\subsubsection{Organizing Culture-Featured Classroom Activities}

Culture-featured classroom activities refer to the activities involving the classroom teaching of related SSET course, such as pair work, group discussion, role-playing, duty report and debate etc., is also a vivid and efficient way to help students cultivate cross-cultural awareness in SSET. The reason for adopting such activities is that not every student has the opportunity to develop personal contact with the native English speakers and experience various cross-cultural communicative activities. For most students, their main exposure to English is in the classroom. Classroom is often called an artificial environment for learning and using a foreign language. So the teacher should try his best to create an environment as authentic and as real-life as possible, provide students with opportunities to use English in "real" communication, such as extending greetings, making appointments, sending or answering a call, presenting gifts, etc. Concerning the JE and NEC, the content of classroom activities of it is very interesting, stimulating and lively. It also meets the English Curriculum Standards (2001, 2011). What's more, if managed well, such activities can be very interesting and absorbing. They are helpful for motivating students to participate in teaching and learning activities more actively. In teaching JE and NEC, such activities can be carried out both in "Reading-Centered Activities" and in "Listening-Centered Activities". Surely, these activities demand much higher requirements for the teacher, but they are actually useful and beneficial for enhancing students' cross-cultural awareness.

\subsection{Cultivation of Cross-Cultural Awareness at Extracurricular Time}

Compared with the classroom instruction, activities at extracurricular time for cultivating secondary students' cross-cultural awareness are often neglected. In fact, because of the restriction of time and space, it is not sufficient for the language learners to only depend on the classroom instruction of foreign culture. As a fact, developing various extracurricular activities to cultivate cross-cultural awareness is interesting and efficient.

\subsubsection{Reading Literary Works}

Among the extracurricular activities, literature reading is thought to be the most commonly used one to increase learners' cultural awareness, especially to explore cross-cultural communication. It is generally accepted that literature is a reflection of society's view, values and beliefs: a reflection of the social, political, cultural development of any society. It reveals people's ideas and dreams in the most creative and imaginative way. Reading literature works including short stories, plays, tales and myths is the better direct way for the students to get to know the foreign culture of the history, geography, customs, traditions, belief and values of the society and to better understand what they have learned in class. These different literary genres can also evoke students' empathy and develop understanding of certain aspects of the other culture. It's widely accepted that the prior knowledge of both the source culture and the target culture can play a positive role in the language learning. The ignorance of the prior experiences may put language acquisition in an unfavorable position. Literature is greatly valuable in enhancing cross-cultural communication in two very important ways. One is by expressing the significance of certain relationships, values, and communication styles, etc. that are representative of the culture being described. The other is by presenting cross-cultural issues themselves as the major theme of the literary work, 
such as acculturation and identity, interethnic relations, and so on.

We should encourage secondary school students to read literature extensively from fiction to nonfiction, from serious writing to children's tales, from literature, arts to philosophy. Reading extensively may not produce an immediate result, but it does help students understand another culture at a deeper level. Literature reading can not only deepen learners' understanding towards foreign countries and their cultures, but also can give students a good insight into the culture.

\subsubsection{Enjoying Films and Songs}

Films offers student opportunities to observe behaviors that are not so obvious in texts. They also provide a more current and comprehensive way of a culture. Film is an authentic window on foreign culture. It connects learners with language and cultural issues simultaneously. There contain a lot of social, political and popular culture contents in English films, and it's easier for us to pick up idioms, slang and to get familiar with both verbal and non-verbal behavior. Film is a super changed medium of communication and a powerful vehicle of information, which provides students with vast space of messages and images about the English culture. As English saying goes: "A picture is worth a thousand words". This is even more so for foreign language learners because they come to know the truth of native speakers' behaviors on the screen or at the stage. The moving pictures bring the real world where English is spoken to the students' eyes and minds, making English language and culture come to life in a way the printed words can't. In accordance with the learners' language proficiency, teachers can select or recommend some appropriate films for presenting the target culture directly and vividly. We suggest using videotapes or films to stimulate discussions on aspects of the target culture. They should be employed as a language and culture learning tool, not just for fun. Students learn various film genres and films dealing with various aspects of western life. We combine the target culture content with developing interpretation and analytical skills, followed up by heated discussions and paper-writing. Watching films is the most effective way to observe non-verbal behaviors of the target culture.

Songs are often used in foreign language classes for teaching vocabulary and grammar, but they can also be a vehicle for the study of culture. According to Chastain (1988: 313), the lyrics and music can be related to people's moods, interests and way of life [16]. And the societal problems treated in a song should be the main concern of the class. Songs work better if students are actively involved, either in discussing the lyrics or participating in singing. Enjoying English songs will also help students to share the feelings and the different life styles of people in English-speaking countries, making students sharp their taste and promote their awareness to English culture.

To sum up, direct experience is the best way to begin to learn any culture. Just as the best way to learn a new language is to become immersed in that language, so too is it most helpful to learn another culture by jumping right in. This may not always be practical, however, especially beneficial for most students and even teachers. Nearly all of the students like watching films and enjoying songs. So the way of enjoying films and songs for cultivating students' cross-cultural awareness will definitely be welcomed by students.

\subsubsection{Surfing the Internet and Reading Web Pages Concerning English Culture Learning}

As the development of the economic globalization and the appearance of the cyber time, computers have been used extensively in education nowadays, and the Internet has gained immense popularity in secondary students' culture learning, through which a large number of information about the target culture can be found. Students are not allowed to surf the Internet in net club because nearly all the students surf the Internet for chatting online or playing computer games which will influence their study, however, Internet can be used in another way. Internet surfing for learning English culture will gain immense popularity in the near future. Through surfing the Internet, a large number of information about target culture will be found. Technology has brought so great a revolution in English teaching that we should make full use of it. Thus, it is worthwhile to encourage students to take advantage of Internet in cultivating their cultural awareness. The application of the Internet makes the cultivation of students' cultural awareness highly efficient. What they need to do is to surf on the Internet with key words through search engines such as "Baidu" etc. Then, relative diversified information such as text, audio or video of English culture learning resources will be appeared. The application of the Internet makes the cultivation of students' cultural awareness highly efficient.

\subsubsection{Task-Based Activities Such as Roleplay and Drama}

Role play can be seen as one of the instructional techniques of social-cultural strategy training. Role play can be 
very effective for experiencing cultural principles and cultural awareness because it gives an opportunity to be emotionally involved in cross-cultural learning and reflects upon cultural differences, and the students learn to examine their perceptions and treat other cultures with empathy.

Using drama to teach English results in real communication involving ideas, emotions, feelings appropriateness and adaptability; in short an opportunity to use language in operation which is absent in a conventional language teaching. Real communication involves ideas, emotions, feelings, appropriateness and adaptability. Such activities add to the teachers' repertoire of pedagogic strategies giving them a wider option of learnercentered activities to choose from. Drama gives a context for listening and meaningful language production, forcing the learners to use their language resources and, thus, enhancing their linguistic abilities. It provides situations for reading and writing. It also involves learners more positively and actively in the text.

In conclusion, these task-based activities are meaningful devices of extra-curricular activities for the students to take part in. Because such activities enable the students to experience their firsthand experience. They involve students emotionally into the situations, and are especially useful for students with little or no experience in a foreign culture. Although these activities are not real experiences, they can make the students realize the state of their English and their communicative competence, and thus make what the students have learned root in their mind permanently. As a result, these activities will stimulate them to further efforts.

\subsubsection{Using Various Aids for Teaching and Learning Culture}

Culture acquisition cannot be achieved merely through classroom teaching. Students should have things relevant to culture to listen to, to talk about, to read, to watch and have personal contact with native speakers if possible. The major causes of students' pragmatic failure are undoubtedly inadequate knowledge of, and insufficient exposure to the target culture as well as a lack of comparative studies of the two cultures. There are some other ways available to change the situation and increase cross-cultural awareness. For instance, encouraging students to develop interpersonal contacts with native speakers or correspond with pen pals in English speaking countries. It is in such relaxed personal contacts that students are apt to pick up some of the cultural information they would not be able to get otherwise. Needless to say, foreign teachers and students who are authentic carriers of their native countries are ideal narrators of their own culture. As English teachers, they should try every possible ways to create opportunities for students to contact with them. They can learn more about cultural background knowledge from foreign teachers and exchange students. They can hear our foreigners' personal and oral explanation about their own culture from daily contact with them face to face, and observe and sense the shades of differences between Western and Chinese cultures through their actions and responses to the existing culture. Apart from the above-mentioned aids for teaching and learning culture, students should be encouraged to listen diversified materials selected. Lectures on cultural background should be made regularly. In addition, English corner is also a good form for learners of English to cooperatively exchange cultural knowledge and practice speaking and listening.

\section{Conclusion}

With years of English study, many students at basic education stage are weak at cross-cultural competence, and it is impossible for them to develop their potential cross-cultural competence. The training of cross-cultural awareness does not usually constitute in curriculum with high expectation without specific outline. That is why the current study has laid emphasis on the explanation and illustration of how to deal with culture teaching and especially in practice what strategies may be employed in order to best cultivate students' cross-cultural awareness and develop their cross-cultural competence. Cultivation of cross-cultural awareness is not only of great necessity but also is one of the most important strands of SSET in China. The thesis points out the accomplishment of cross-cultural awareness cultivation eventually depends on the involvement of the relevant strategies, approaches, techniques and activities in the course of Secondary English teaching and learning. We must view raising cross-cultural awareness in English education as a means not just of improving the quality of SSET, but also of promoting key competencies by means of cooperation and friendship among different peoples and nations. With qualification — for life education being made the objective of and fostering students' key competencies in Chinese education at all levels, professionals are striving for improving students' cultural qualifications. Much evidence shows that cross-cultural communication is not an easy assignment, but that does not mean it is not worthwhile or is to be avoided. We have no choice given. Within the waning hours of the new millennium, if we are going to survive in the global village, we must strive to become effective and successful cross-cultural 
communicators. As a matter of fact, gaining cross-cultural awareness can be exciting, and enjoyable and rewarding. Cultivating secondary school students' cross-cultural awareness is a long term practical task. The ultimate teachers' goal should be to develop intrinsic motivation in their students. If students' intrinsic motivation is aroused, they will pursue their English learning by making better use of their curricular time and extra-curricular time in learning materials containing alien cultures and this will eventually foster their cross-cultural awareness and develop key competencies.

\section{Acknowledgements}

The study reported in this article was supported by the Key Research Bases of Humanities and Social Science, Research Centre for Basic Education, Southwest University, Chongqing, China (Project Code: 20500105). The findings and opinions expressed in the article are those of the author and do not necessarily reflect the positions of the funding agencies.

\section{References}

[1] Ministry of Education (2001) English Curriculum Standards for Compulsory Education. Beijing Normal University Publishing Group, Beijing.

[2] Ministry of Education (2011) English Curriculum Standards for Compulsory Education. Beijing Normal University Publishing Group, Beijing.

[3] Brown, H.D. (2001) Teaching by Principles: An Interactive Approach to Language Pedagogy. Foreign Language Teaching and Research Press, Beijing.

[4] Rivers, W.M. (1997) Interactive Language Teaching. Foreign Language Teaching and Research Press, Beijing.

[5] Carrell, P.L. (1988) Interactive Approaches to Second Language Reading. Cambridge University Press, Cambridge. http://dx.doi.org/10.1017/CBO9781139524513

[6] Gaudiani, C. (1981) Teaching Writing in the FL Curriculum. Oxford University Press, New York.

[7] Ur, P. (1996) A Course in Language Teaching Practice and Theory. Cambridge University Press, Cambridge.

[8] Valdes, J.M. (1986) Culture Bound: Bridging the Cultural Gap in Language Teaching. Cambridge University Press, Cambridge.

[9] Raimes, A. (1983) Techniques in Teaching Writing. Oxford University Press, New York.

[10] Nostrand, H.L. (1989) Authentic Texts-Cultural Authenticity: An Editorial. Modern Language Journal, 73, 1. http://dx.doi.org/10.1111/j.1540-4781.1989.tb05310.x

[11] Hammerly, H. (1982) Synthesis in Second Language Teaching. Second Language Publications, Blaine.

[12] Seelye, H.N. (1984) Teaching Culture. National Textbooks Company, Lincolnwood.

[13] Sapir, E. (1921) Language: An Introduction to the Study of Speech. Harcourt Barace Jovanovich, Inc., New York.

[14] Wierzbicka, A. (1997) Understanding Culture Through Their Key Words: English, Russian, Polish, German, and Japanese. Oxford University, New York.

[15] Coady, J. (1979) A Psycholinguistic Model of the ESL Reader. In: Ronald, M. and Bruce, B., Eds., Reading in a Second Language, Newbury House Publishers, Rowley, 5-12.

[16] Chastain, K. (1988) Developing Second Language Skills. Theory and Practice. Harcourt Brace Janovich Publishers, Orlando. 


\section{Submit or recommend next manuscript to SCIRP and we will provide best service for you:}

Accepting pre-submission inquiries through Email, Facebook, Linkedin, Twitter, etc A wide selection of journals (inclusive of 9 subjects, more than 200 journals)

Providing a 24-hour high-quality service

User-friendly online submission system

Fair and swift peer-review system

Efficient typesetting and proofreading procedure

Display of the result of downloads and visits, as well as the number of cited articles

Maximum dissemination of your research work

Submit your manuscript at: http://papersubmission.scirp.org/ 